\title{
Aluminum Group Extraction with Benzoic Acid - Acetic Acid Crossed Type Calix[4]arene Derivatives
}

\author{
Makoto KAWASHIMA ${ }^{1}$, Hidetaka KAWAKITA ${ }^{1}$, Keisuke OHTO $^{1} *$ and Yuzo SHIWA ${ }^{2}$ \\ ${ }^{1}$ Department of Chemistry and Applied Chemistry, Saga University, 1-Honjo, Saga 840-8502, Japan \\ ${ }^{2}$ Saga Ceramics Research Laboratory, 3037-7 Kuromuta, Arita-cho, Saga 844-0022, Japan \\ (Received January 31, 2012; accepted February 13, 2012)
}

\begin{abstract}
A calix[4]arene carboxylic acid derivative alternatively possessing benzoic acid and two acetic acid groups has been prepared to investigate the extraction behavior for the aluminum group of metals, such as aluminum, gallium, and indium from nitrate and chloride media and to compare with the tetraacetic acid derivative. The present extraction reagent exhibits a simple ion-exchange mechanism for all metals. Both extractants show that the selectivity series is $\mathrm{In}>\mathrm{Ga} \gg \mathrm{Al}$ in nitrate media, while $\mathrm{Ga}>\mathrm{In}>>\mathrm{Al}$ is found for chloride media due to complexation of indium with chloride anions. The stoichiometry of the gallium complex with both extractants, determined by the continuous variation method, was determined to be $1: 1$. The complexation site of the present extractant for gallium was also determined using ${ }^{1} \mathrm{H}-\mathrm{NMR}$ spectroscopy. The extraction ability and separation efficiency of both extractants for the three metal ions were estimated by using the half $\mathrm{pH}$ values. Stripping of the metal ions loaded on the present extractant with hydrochloric acid was also investigated.
\end{abstract}

\section{Introduction}

Gallium and indium are present in trace amounts in zinc ores such as zinc blende. Demand for these metals has increased since they are extensively used in advanced materials such as semiconductors for the electronic industry. Effective recovery and recycle of such valuable metals has grown in importance in recent years. For such a requirement, some new extraction reagents have been prepared [1-5].

Calixarenes and their derivatives have been attracting much attention as novel types of interesting host compounds. Their recognizing ability and discriminating functionality for metal ions are remarkable features as specific receptors due to (1)a rigid macrocyclic structure for selectivity; (2)having cyclic phenolic hydroxyl groups for chemical modification; (3)having multifunctionality for high extractability [6-10]. Specific properties have been also reported by our group [11-14] and in particular, such ion-discriminating compounds are effective for the mutual separation of cognatic atoms of different size. In previous work, although the tetraacetic acid derivative of $p$-t-octylcalix[4]arene ('Oct[4]Ac) was synthesized to investigate the extraction behavior of various metal ions, the extraction behavior of the aluminum group ions has not been investigated in detail $[15,16]$.

In the present work, we have prepared a benzoic acid - acetic acid crossed type $p$-t-octylcalix[4]arene 


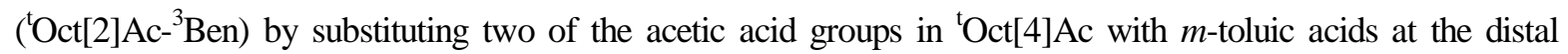
position to provide improved separation efficiency of the aluminum group metals by attaching rigid functional groups. The chemical structures of the present and the comparative extractants are shown in Figure.1.
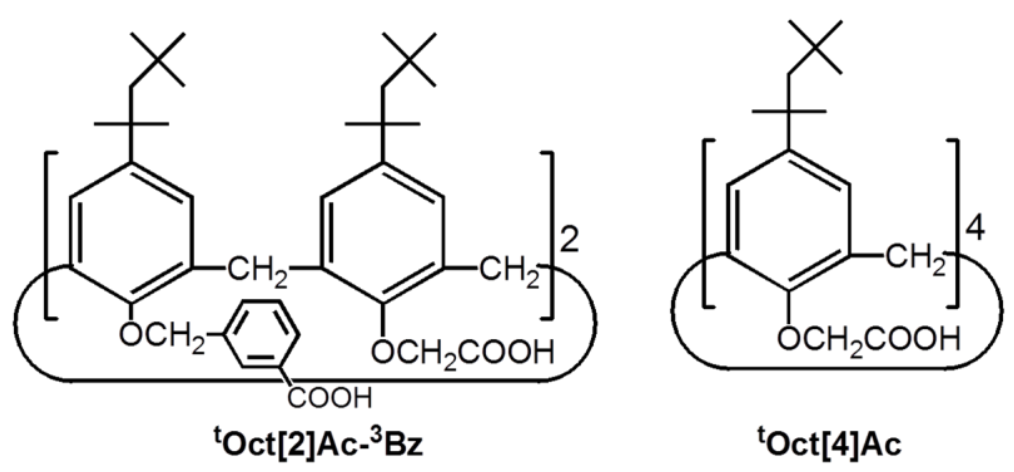

Figure 1. Chemical structures of the extractants.

\section{Experimental}

\subsection{Reagents}

25,26,27,28-Tetrakis(carboxymethoxy)-5,11,17,23-tetrakis(1,1,3,3-tetramethylbutyl) calix[4]arene as

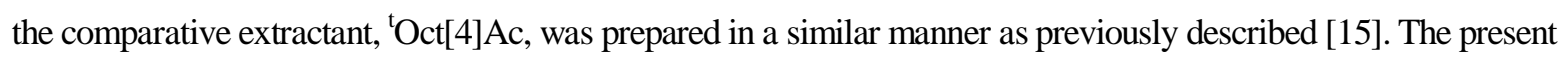
extractant, ${ }^{\mathrm{t} O c t}[2] \mathrm{Ac}-{ }^{3} \mathrm{Ben}$, has been prepared in four steps of cyclization, disubstitution of acetate at the distal position, the complete substitution of benzoate on the remaining phenol oxygen atoms, and final hydrolysis with base from $p$-t-octylphenol. Both extractants are in cone conformation wherein all carboxylic acids point in to the same direction. The synthetic scheme of the present extractant, ${ }^{\mathrm{t} O c t}[2] \mathrm{Ac}-{ }^{3} \mathrm{Ben}$ is shown in Figure 2. Other chemicals were of analytical grade and employed without further purification.

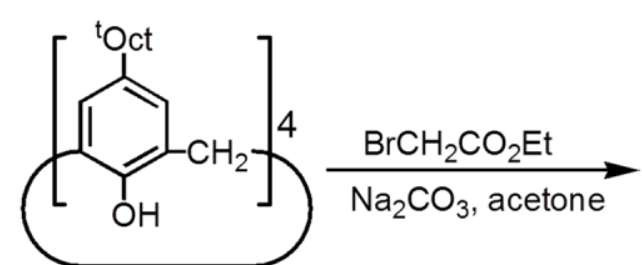

1

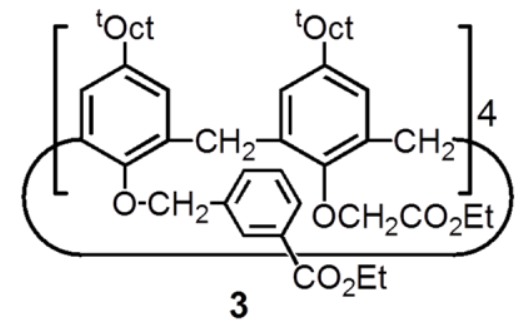

$\underline{3}$

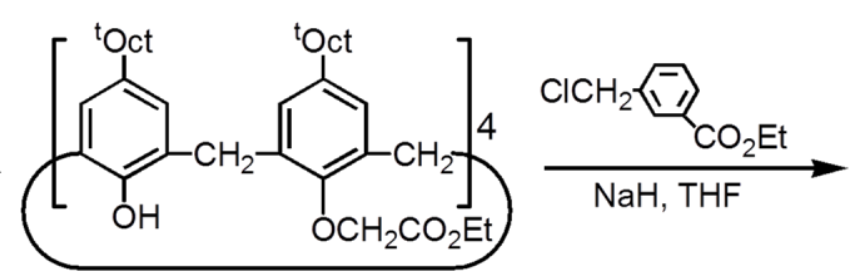

$\underline{2}$

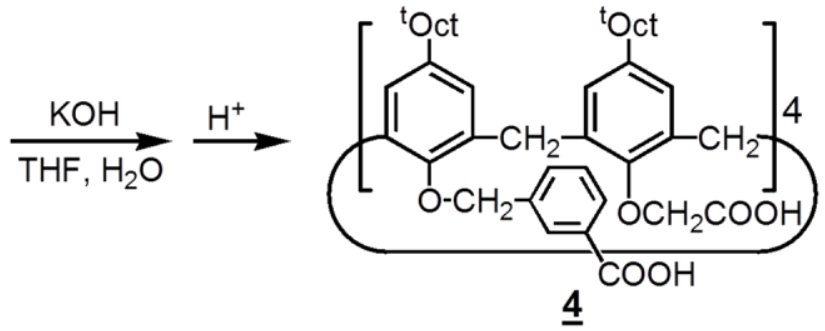

Figure 2. Synthetic scheme of the present extractant. 
5,11,17,23-Tetrakis(1,1,3,3-tetramethylbutyl)calix[4]arene-25,26,27,28-tetrol was prepared in a similar manner as previously described [15].

25,27-Bis(ethoxycarbonylmethoxy)-26,28-dihydroxy-5,11,17,23-tetrakis(1,1,3,3-tetramethylbutyl)calix[4]arene (2)

p-t-Octylcalix[4]arene, $\underline{\mathbf{1}}, 10.0 \mathrm{~g}$ (11.5 mmol), ethyl bromoacetate $3.82 \mathrm{~g}(22.9 \mathrm{mmol}, 2 \mathrm{eq})$ and sodium carbonate $1.46 \mathrm{~g}(13.7 \mathrm{mmol} 1.2 \mathrm{eq})$ were mixed in $300 \mathrm{~cm}^{3}$ of dry acetone. In a nitrogen atmosphere, the mixture was refluxed for $45 \mathrm{~h}$. After filtration, the solvent was evaporated. The residue was dissolved in chloroform. The organic layer was washed with $1 \mathrm{M}\left(\mathrm{M}=\mathrm{mol} \mathrm{dm}^{-3}\right)$ hydrochloric acid and then distilled water three times and was then dehydrated over anhydrous $\mathrm{MgSO}_{4}$. After filtration, the solvent was evaporated. The residue was recrystallized from ethanol to give a white powder $7.42 \mathrm{~g}$ (yield : 62.0\%). TLC $\left(\mathrm{SiO}_{2}, \mathrm{CHCl}_{3}\right) R_{\mathrm{f}}=0.11$; FT-IR $(\mathrm{KBr}) v_{\mathrm{O}-\mathrm{H}} 3435(\mathrm{~s}), v_{\mathrm{C}-\mathrm{H}} 2954(\mathrm{~s}), v_{\mathrm{C}=\mathrm{O}} 1763$ (s), $v_{\mathrm{C}-\mathrm{O}} 1207$ (s) $\mathrm{cm}^{-1} ;{ }^{1} \mathrm{H}-\mathrm{NMR}\left(300 \mathrm{MHz}, \delta, \mathrm{CDCl}_{3}\right.$, TMS, $\left.25^{\circ} \mathrm{C}\right) 0.27\left(\mathrm{~s}, 18 \mathrm{H}, \mathrm{C}\left(\mathrm{CH}_{3}\right)_{3}\right), 0.71\left(\mathrm{~s}, 18 \mathrm{H}, \mathrm{C}\left(\mathrm{CH}_{3}\right)_{3}\right), 1.09\left(\mathrm{~s}, 12 \mathrm{H}, \mathrm{C}\left(\mathrm{CH}_{3}\right)_{2}\right), 1.35(\mathrm{~s}+\mathrm{t}, 12 \mathrm{H}+6 \mathrm{H}$,

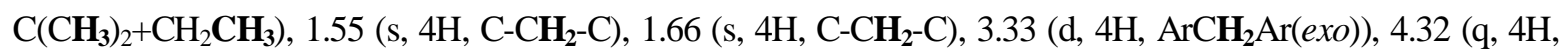
$\mathrm{CH}_{2} \mathrm{CH}_{3}$ ), 4.45 (d, 4H, $\operatorname{ArCH} \mathbf{H}_{2} \operatorname{Ar}\left(\right.$ endo) ), 4.65(s, 4H, OCH ${ }_{2} \mathrm{COO}$ ), 6.83(s, 4H, $\left.\operatorname{ArH}\right), 6.99$ (s, 4H, $\left.\operatorname{ArH}\right), 7.28(\mathrm{~s}$, $2 \mathrm{H}, \mathrm{OH})$.

25,27-Bis(ethoxycarbonylmethoxy)-26,28-bis(ethoxycarbonyl-3-benzyloxy)-5,11,17,23-tetrakis(1,1,3,3-tetramet hylbutyl)calix[4]arene ( $\underline{\mathbf{3}})$

The disubstituted compound, $\underline{\mathbf{2}}, 7.00 \mathrm{~g}(6.69 \mathrm{mmol})$ and sodium hydride $3.21 \mathrm{~g} \mathrm{(60 \%} \mathrm{in} \mathrm{oil} \mathrm{,} 80.3$ mmol , 12eq) were mixed in $100 \mathrm{~cm}^{3}$ of dry $N, N$-dimethylformamide (DMF). In a nitrogen atmosphere, the mixture was stirred at $303 \mathrm{~K}$ for a half hour. After ethyl 3-(chloromethyl)benzoate $10.6 \mathrm{~g}(53.5 \mathrm{mmol}$, 8eq) was added, the mixture was stirred at $303 \mathrm{~K}$ for $48 \mathrm{~h}$. After excess sodium hydride was deactivated with ethanol, the solvent was evaporated in vacuo. The residue was dissolved in chloroform. The organic layer was washed with 1 $\mathrm{M}$ hydrochloric acid and then distilled water three times, and was dehydrated over anhydrous $\mathrm{MgSO}_{4}$. After filtration, the solvent was evaporated. The residue was recrystallized from acetonitrile and chloroform to give a white powder $3.26 \mathrm{~g}$ (yield : $35.6 \%)$. TLC $\left(\mathrm{SiO}_{2}, \mathrm{MeOH}\right): R_{\mathrm{f}}=0.00$; FT-IR $(\mathrm{KBr})$ disappeared peak $v_{\mathrm{O}-\mathrm{H}} 3435$ (s), $v_{\mathrm{C}=\mathrm{O}}$ (aliphatic) 1761 (s), $v_{\mathrm{C}=\mathrm{O}}$ (aromatic) $1722(\mathrm{~s}), v_{\mathrm{C}-\mathrm{O}} 1201(\mathrm{~s}) \mathrm{cm}^{-1} ;{ }^{1} \mathrm{H}-\mathrm{NMR}\left(300 \mathrm{MHz}, \delta, \mathrm{CDCl}_{3}, \mathrm{TMS}\right.$, $\left.25^{\circ} \mathrm{C}\right)$ 0.53(s, $\left.18 \mathrm{H}, \mathrm{C}\left(\mathrm{CH}_{3}\right)_{3}\right), 0.74$ (s, 18H, $\left.\mathrm{C}\left(\mathrm{CH}_{3}\right)_{3}\right), 0.84$ (s, 12H, $\left.\mathrm{C}\left(\mathrm{CH}_{3}\right)_{2}\right), 1.32$ (s, 12H, $\left.\mathrm{C}\left(\mathrm{CH}_{3}\right)_{2}\right), 1.38$ (s+t, $\left.4 \mathrm{H}+6 \mathrm{H}, \quad \mathrm{C}-\mathrm{CH}_{2}-\mathrm{C}+\mathrm{CH}_{2} \mathbf{C H}_{3}\right), 1.68$ (s, 4H, C-CH $\left.-\mathbf{C H}_{2}-\mathrm{C}\right), 2.87$ (d, 4H, $\operatorname{ArCH} \mathbf{H}_{2} \operatorname{Ar}($ exo $)$ ), 3.90 (d, 4H, $\operatorname{ArCH} \mathbf{H}_{2} \operatorname{Ar}(e n d o)$ ), 4.34 (q, 4H, $\mathrm{CH}_{2} \mathrm{CH}_{3}$ ), 4.57 (s, 4H, O-CH $\mathbf{C H}_{2}-\mathrm{Ar}$ ), 5.02 (s, 4H, OCH $\mathbf{H}_{2} \mathrm{COO}$ ), 6.53 (s, 4H, HAr-OCH ${ }_{2} \mathrm{Ar}$ ), 7.01 (s, $4 \mathrm{H}, \mathbf{H A r}-\mathrm{OCH}_{2} \mathrm{COO}$ ), 7.36 (d, 2H, OCH $2 \mathrm{Ar}-o \mathbf{H}$ ), 7.42 (t, 2H, OCH $\left.\mathrm{OCH}_{2} \mathrm{Ar} \mathbf{H}\right)$ ), 7.83 (d, $\left.\left.2 \mathrm{H}, \mathrm{OCH}_{2} \mathrm{Ar}-p \mathbf{H}\right)\right), 8.08$ (s, $\left.2 \mathrm{H}, \mathrm{OCH}_{2} \mathrm{Ar}-o \mathbf{H} m \mathrm{COO}\right)^{*}$.

*Ethyl acetate group derived proton peak $\left(\mathrm{CH}_{2} \mathrm{CH}_{3}\right)$ could not be found. Most of the ester groups may be hydrolyzed during the aftertreatment of benzoate introduction.

25,27-Bis(carboxylmethoxy)-26,28-bis(carboxyl-3-benzyloxy)-5,11,17,23-tetrakis(1,1,3,3-tetramethylbutyl)calix [4]arene $\left(\underline{4}:{ }^{\mathrm{t}} \mathrm{Oct}[2] \mathrm{Ac}-{ }^{3} \mathrm{Ben}\right)$

The tetrasubstituted ester compound, $\underline{\mathbf{3}}, 1.00 \mathrm{~g}(0.730 \mathrm{mmol})$ was dissolved in $200 \mathrm{~cm}^{3}$ THF. Potassium hydroxide $0.820 \mathrm{~g}$ (14.6 mmol, 20eq) in $30.0 \mathrm{~cm}^{3}$ distilled water was added to the solution. The mixture was refluxed for $24 \mathrm{~h}$. After the mixture was neutralized with $6 \mathrm{M}$ hydrochloric acid, the solvent was 
evaporated. The residue was dissolved with warm chloroform for better solubility, and the organic solution was washed with $1 \mathrm{M}$ hydrochloric acid and then distilled water three times. The organic solution was dried over anhydrous $\mathrm{MgSO}_{4}$. After the warm mixture was filtered, the solvent was evaporated. The residue was reprecipitated using acetonitrile, and then $0.720 \mathrm{~g}$ of a white powder was obtained (yield : 78.3\%). TLC $\left(\mathrm{SiO}_{2}\right.$, $\mathrm{MeOH}): R_{\mathrm{f}}=0.00 ; \mathrm{FT}-\mathrm{IR}(\mathrm{KBr}) v_{\mathrm{C}=\mathrm{O}}$ (aliphatic) $1728(\mathrm{~s}), v_{\mathrm{C}=\mathrm{O}}$ (aromatic) $1699(\mathrm{~s}) \mathrm{cm}^{-1} .{ }^{1} \mathrm{H}-\mathrm{NMR}(300 \mathrm{MHz}$, $\left.\delta, \mathrm{CDCl}_{3}, \mathrm{TMS}, 25^{\circ} \mathrm{C}\right) 0.51$ (s, 18H, $\left.\mathrm{C}\left(\mathrm{CH}_{3}\right)_{3}\right), 0.75\left(\mathrm{~s}, 18 \mathrm{H}, \mathrm{C}\left(\mathrm{CH}_{3}\right)_{3}\right), 0.90\left(\mathrm{~s}, 12 \mathrm{H}, \mathrm{C}\left(\mathrm{CH}_{3}\right)_{2}\right), 1.34(\mathrm{~s}, 12 \mathrm{H}$,

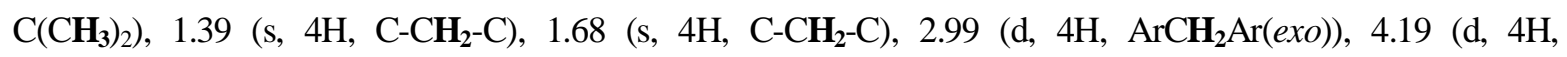

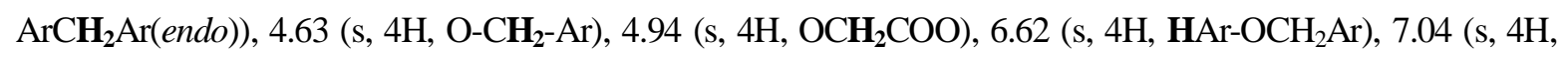
HAr- $\mathrm{OCH}_{2} \mathrm{COOH}$ ), 7.21 (d, 2H, OCH $\left.2 \mathrm{Ar}-o \mathbf{H}\right), 7.34$ (t, $\left.2 \mathrm{H}, \mathrm{OCH}_{2} \mathrm{Ar}-m \mathbf{H}\right)$ ), 8.10 (d, $\left.2 \mathrm{H}, \mathrm{OCH}_{2} \mathrm{Ar}-p \mathbf{H}\right)$ ), 8.35 (s, $\left.2 \mathrm{H}, \mathrm{OCH}_{2} \mathrm{Ar}-o \mathbf{H} m \mathrm{COOH}\right)$.

\subsection{Distribution study}

Organic solutions were prepared by diluting the extractant with analytical grade chloroform to the desired concentration $(5 \mathrm{mM})$. Aqueous solutions were prepared by dissolving each metal chloride to the desired concentration in 0.1 M hydrochloric acid or 0.1 M HEPES (2-[4-(2-hydroxyethyl)-1-piperazinyl]ethane sulfonic acid) solution. They were arbitrarily mixed to adjust the initial $\mathrm{pH}$ of the aqueous solution. Equal volumes $\left(4 \mathrm{~cm}^{3}\right)$ of both phases were mixed and shaken at $303 \mathrm{~K}$ for more than $24 \mathrm{~h}$, which was sufficient to attain equilibrium. After phase separation, metal concentrations and $\mathrm{pH}$ values in the aqueous phase were measured by ICP-AES (Shimadzu, ICPS-8100) and a pH meter (TOA-DKK, HM-30R), respectively. The amounts of the extracted metal ions were calculated from the differences of the metal concentrations in the aqueous phase before and after equilibrium. In the continuous variation method, the total concentration of metal ion and the extractant was kept constant at $1 \mathrm{mM}$.

\subsection{Proton nuclear magnetic resonance study of the main complexes}

The experiment was carried out in a similar manner to the distribution study except for the use of analytical grade deuterium solvents $\left(\mathrm{D}_{2} \mathrm{O}\right.$ and $\left.\mathrm{CDCl}_{3}\right)$ instead of distilled water and analytical grade chloroform. After phase separation, the peaks and the integral ratios of the extractant in the organic phase were recorded by a nuclear magnetic resonance spectrophotometer (Jeol, JNM-AL300).

\subsection{Stripping of the loaded metal ions}

The organic phase wherein metal ions were quantitatively loaded in the forward extraction, and fresh hydrochloric acid aqueous solution were mixed and shaken at $303 \mathrm{~K}$ for $24 \mathrm{~h}$. After phase separation, the metal concentrations in the strip aqueous solution were measured by ICP-AES.

\subsection{Distribution study}

\section{Results and discussion}

Firstly, the extraction time was investigated. The effect of shaking time on the percentage extraction of aluminum, gallium, and indium with the present extractant is shown in Figure 3. Among the aluminum group metal ions, the ligand exchange rate for aluminum is expected to be slow based on the Eigen mechanism [17]. Furthermore, although the extraction samples were mildly shaken at $130 \mathrm{rpm}$, aluminum extraction reached equilibrium within $6 \mathrm{~h}$. Although the extraction rates of gallium and indium are expected to be faster than that of 
aluminum by the Eigen mechanism, those of all ions in the present work are almost the same.

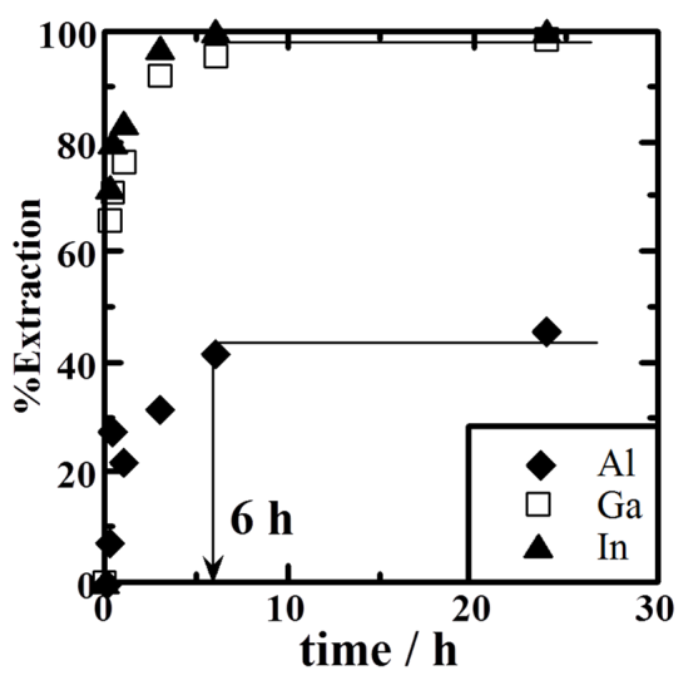

Figure 3. Effect of shaking time on the percentage extraction of aluminum group metal ions with 'Oct[2]Ac- ${ }^{3}$ Ben. $[$ Metal] $=0.1 \mathrm{mM}$, [extractant $]=5 \mathrm{mM}$, initial $\mathrm{pH}=3.50\left(0.1 \mathrm{M} \mathrm{HNO}_{3}-0.1 \mathrm{M} \mathrm{HEPES}\right)$.

The effects of $\mathrm{pH}$ on the distribution ratio for aluminum, gallium, and indium with both extractants in nitrate media are shown in Figures 4(a) and (b). All points in Figure 4 lie on straight lines with slopes of 3, which is equivalent to the charge of the aluminum group metal ions, although the lines for aluminum and gallium extraction with ${ }^{\mathrm{t} O c t}[4] \mathrm{Ac}$ are not actually straight. The result indicates that all trivalent metal ions are ion-exchanged with three protons from both extractants. The $\mathrm{pH}$ region for aluminum group metal extraction with ${ }^{t} \mathrm{Oct}[2] \mathrm{Ac}-{ }^{3} \mathrm{Ben}$ is almost the same as that for ${ }^{\mathrm{t}} \mathrm{Oct}[4] \mathrm{Ac}$. This means that the extraction ability of both extractants is almost the same. The $\mathrm{p} K_{\mathrm{a}}$ value of 3-methylbenzoic acid as a reference compound for ${ }^{\mathrm{t}} \mathrm{Oct}[2] \mathrm{Ac}-{ }^{3} \mathrm{Ben}, 4.27$

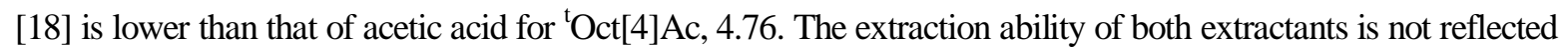
as expected by the $\mathrm{p} K_{\mathrm{a}}$ values. Tetraacetic acid, 'Oct[4]Ac possesses four equivalent acetic acids, consequently they complementarily act in the extraction. In contrast, ${ }^{\mathrm{t} O c t}[2] \mathrm{Ac}-{ }^{3} \mathrm{Ben}$ has two different carboxylic acids, which provide weak complementarity and a rugged coordination site. Furthermore, since the benzoic acid in ${ }^{\mathrm{t} O c t}[2] \mathrm{Ac}-{ }^{3} \mathrm{Ben}$ is located at the meta position, if a metal ion complex is formed with the carboxylic acids, together with the phenoxy oxygen atoms, complexation with ${ }^{\mathrm{t}} \mathrm{Oct}[2] \mathrm{Ac}-{ }^{3} \mathrm{Ben}$ is apparently not preferred. The structural rigidity of the benzoic acid introduced in ${ }^{\mathrm{t}} \mathrm{Oct}[2] \mathrm{Ac}-{ }^{3} \mathrm{Ben}$ may also relate to the decrease in extraction ability. Consequently, the extraction ability of both extractants seems to be similar. The extraction selectivity for both extractants is similar i.e. In $>\mathrm{Ga}>\mathrm{Al}$. Although a precise evaluation of the mutual separation efficiency of the aluminum group metal ions with both extractants will be discussed later, separation efficiency between the three metal ions seems to be roughly the same, since the distances between the lines are same for both extractants.

The effect of $\mathrm{pH}$ on the distribution ratio for aluminum, gallium, and indium with both extractants in nitrate media are shown in Figures 5 (a) and (b). All points also lie on straight lines with slopes of 3, equivalent to the charge on the aluminum group metal ions. So, in this media all trivalent metal ions are ion-exchanged with three protons from both extractants. The $\mathrm{pH}$ region for indium extraction with ${ }^{\mathrm{t} O c t}[2] \mathrm{Ac}-{ }^{3} \mathrm{Ben}$ is slightly higher 
than that for ${ }^{t} \mathrm{Oct}[4] \mathrm{Ac}$. In addition, the extraction region for both extractants in chloride media is higher than that in nitrate media. Chloride ion apparently suppresses metal complexation, especially for indium. Thus, the extraction selectivity in chloride media is similar for both extractants and is different from that for nitrate media, $\mathrm{Ga}>\mathrm{In}>\mathrm{Al}$. The suppressed extraction and different extraction selectivity may contribute to the different extraction ability of both extractants in chloride media. Although the precise evaluation of the mutual separation efficiency of the aluminum group metal ions will be discussed later, the separation efficiency between gallium and indium ions with ${ }^{\mathrm{t} O c t}[2] \mathrm{Ac}-{ }^{3} \mathrm{Ben}$ seems to be better than that for ${ }^{\mathrm{t}} \mathrm{Oct}[4] \mathrm{Ac}$. Regardless of the lower $\mathrm{p} K_{\mathrm{a}}$

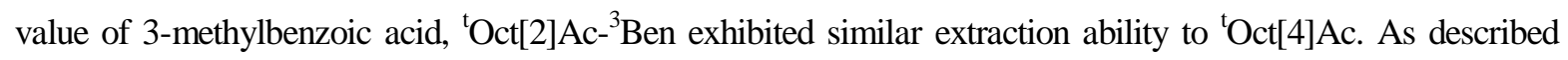
above, the similar ability for both extractants is accidental due to some factors such as less complementarity, less chelation based on the position of the functional groups, the structural rigidity of ${ }^{t} \mathrm{Oct}[2] \mathrm{Ac}-{ }^{3} \mathrm{Ben}$ compared with

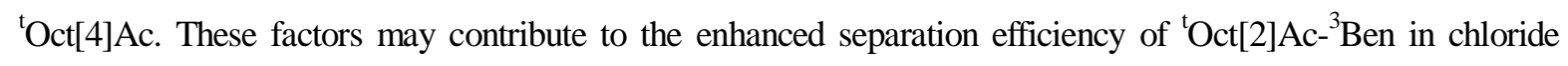
media.

Although extraction equilibrium constants and separation factors based on complexation with chloride ions are not estimated in the present paper, half $\mathrm{pH}$ values and half $\mathrm{pH}$ value differences are used for quantitatively discussion. Half $\mathrm{pH}$ values, $\mathrm{pH}_{1 / 2}$ for aluminum group metal extraction with both extractants and half $\mathrm{pH}$ value differences, $\Delta \mathrm{pH}_{1 / 2}$ are listed in Table 1 . The relative extraction ability and separation efficiency of both extractants have been roughly described above. The half $\mathrm{pH}$ value differences between gallium and indium ions are noted for a precise discussion of separation efficiency. The $\Delta \mathrm{pH}_{1 / 2}$ values of $\mathrm{Ga}^{3+} / \mathrm{In}^{3+}$ for ${ }^{\mathrm{t}} \mathrm{Oct}[4] \mathrm{Ac}$ and ${ }^{\mathrm{t} O c t}[2] \mathrm{Ac}-{ }^{3} \mathrm{Ben}$ in nitrate media are 0.19 and 0.25 , respectively, while those in chloride media are -0.12 and -0.18 . The separation efficiency of ${ }^{t} \mathrm{Oct}[2] \mathrm{Ac}^{-}{ }^{3} \mathrm{Ben}$ is slightly higher than that of ${ }^{\mathrm{t}} \mathrm{Oct}[4] \mathrm{Ac}$. The suppression of indium extraction for ${ }^{\mathrm{t} O c t}[2] \mathrm{Ac}-{ }^{3} \mathrm{Ben}(0.43)$ is more significant than that for ${ }^{\mathrm{t}} \mathrm{Oct}[4] \mathrm{Ac}(0.31)$. It is clearly attributed to the factors described above, that is, to structural effects caused by the introduction of benzoic acid. Thus, the substitution of acetic acid with benzoic acid contributes to separation between gallium and indium ions, especially in chloride media due to indium rejection.
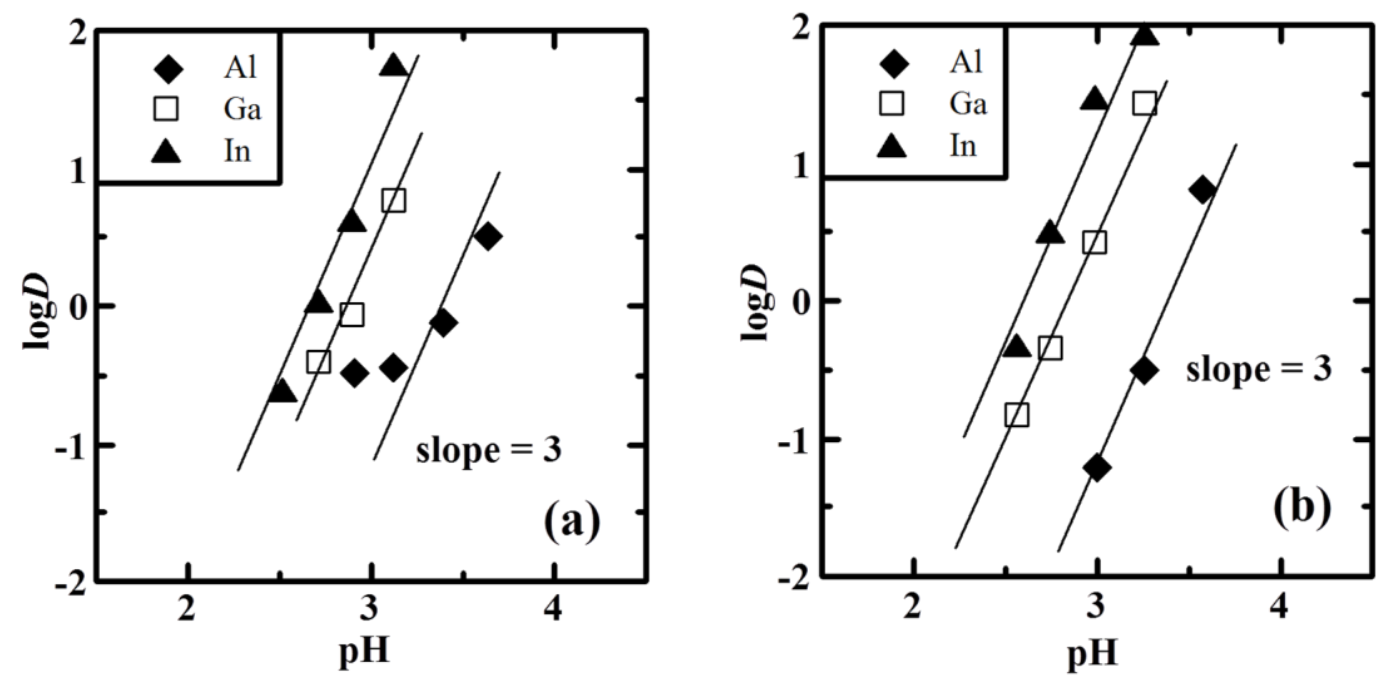

Figure 4. Effect of $\mathrm{pH}$ on the distribution ratio for aluminum, gallium, and indium ions with (a) ${ }^{\mathrm{t}} \mathrm{Oct}[4] \mathrm{Ac}$, (b) ${ }^{\mathrm{t} O c t}[2] \mathrm{Ac}-{ }^{3} \mathrm{Ben}$ in nitrate media. [Metal] $=0.1 \mathrm{mM}$, [extractant $]=5 \mathrm{mM}, 0.1 \mathrm{M} \mathrm{HNO}_{3}-0.1 \mathrm{M} \mathrm{HEPES}$. 

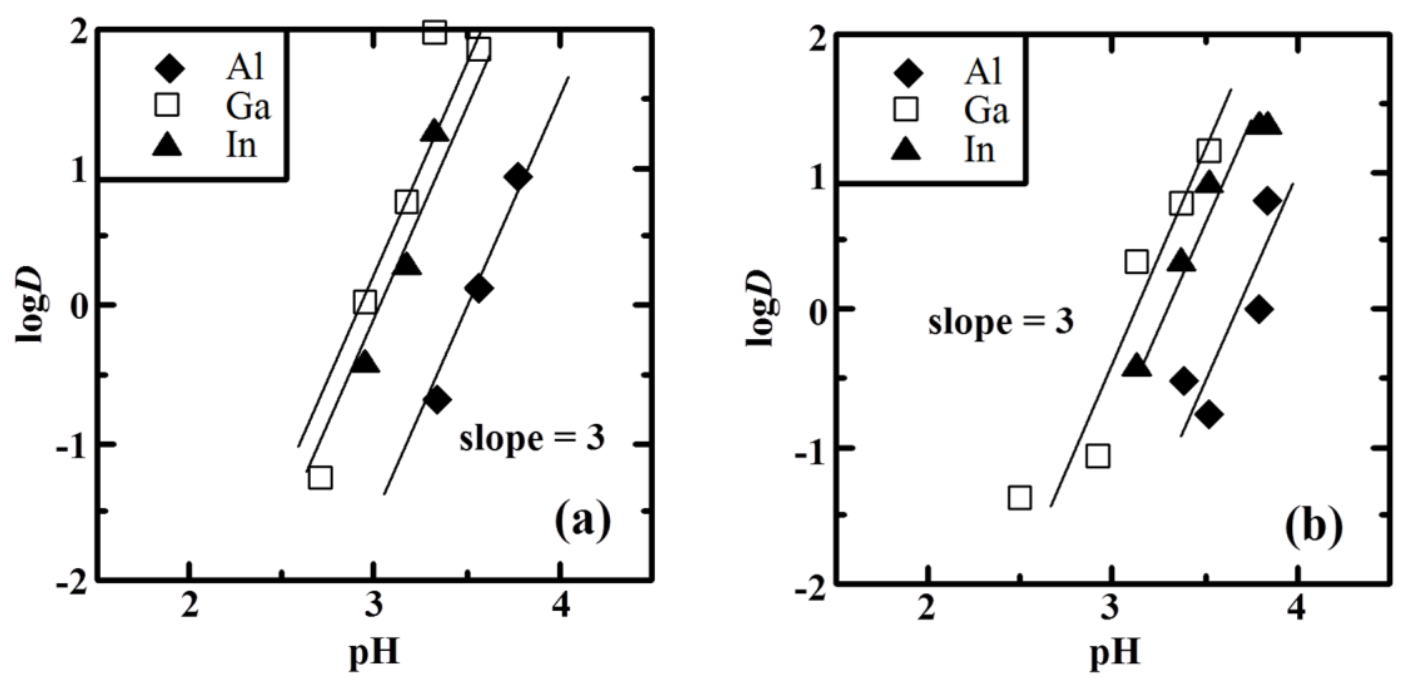

Figure 5. Effect of $\mathrm{pH}$ on the distribution ratio for aluminum, gallium, and indium ions with (a) ${ }^{\mathrm{t}} \mathrm{Oct}[4] \mathrm{Ac}$, (b) ${ }^{\mathrm{t} O c t}[2] \mathrm{Ac}-{ }^{3} \mathrm{Ben}$ in chloride media. [Metal] $=0.1 \mathrm{mM}$, [extractant] $=5 \mathrm{mM}, 0.1 \mathrm{M} \mathrm{HCl}-0.1 \mathrm{M}$ HEPES.

Table 1. Half $\mathrm{pH}$ values, $\mathrm{pH}_{1 / 2}$ for aluminum group metal extraction with both extractants and half $\mathrm{pH}$ value differences, $\Delta \mathrm{pH}_{1 / 2}$.

\begin{tabular}{ccccc}
\hline \multirow{2}{*}{ Media } & \multirow{2}{*}{ Extractant } & \multicolumn{3}{c}{$\mathrm{pH}_{1 / 2}$} \\
\cline { 3 - 5 } & & $\mathrm{Al}^{3+}$ & $\mathrm{Ga}^{3+}$ & $\mathrm{In}^{3+}$ \\
\hline \hline \multirow{2}{*}{ Nitrate media } & 'Oct[4]Ac & 3.38 & 2.86 & 2.67 \\
& Oct[2]Ac- ${ }^{3+} \mathrm{Ben}$ & 3.38 & 2.83 & 2.58 \\
\hline \hline \multirow{2}{*}{ Chloride media } & & $\mathrm{Al}^{3+}$ & $\mathrm{Ga}^{3+}$ & $\mathrm{In}^{3+}$ \\
& 'Oct[4]Ac & 3.50 & 2.91 & 3.03 \\
& 'Oct[2]Ac- ${ }^{3} \mathrm{Ben}$ & 3.68 & 3.12 & 3.30 \\
\hline
\end{tabular}

\begin{tabular}{cc}
\hline \multicolumn{2}{c}{$\Delta \mathrm{pH}_{1 / 2}$} \\
\hline $\mathrm{Al}^{1+} / \mathrm{Ga}^{3+}$ & $\mathrm{Ga}^{3+} / \mathrm{In}^{3+}$ \\
\hline \hline 0.52 & 0.19 \\
0.55 & 0.25 \\
\hline $\mathrm{Al}^{3+} / \mathrm{Ga}^{3+}$ & $\mathrm{Ga}^{3+} / \mathrm{In}^{3+}$ \\
\hline \hline 0.59 & -0.12 \\
0.56 & -0.18 \\
\hline
\end{tabular}

Another experiment was carried out for determination of the extraction reaction for gallium, which is less suppressed by chloride ions and less hydrolyzed. The continuous variation method was performed to confirm the stoichiometry of the extraction reaction for ${ }^{\mathrm{t} O c t}[4] \mathrm{Ac}$ and ${ }^{\mathrm{t} O c t}[2] \mathrm{Ac}^{-3} \mathrm{Ben}$ with gallium. The Job's plots for gallium with ${ }^{\mathrm{t} O c t[4] A c}$ and ${ }^{\mathrm{t} O c t[2] A c-}{ }^{3}$ Ben are shown in Figures 6(a) and (b). Gallium was found to form $1: 1$ metal: extractant complexes with both extractants. From the results of $\mathrm{pH}$ dependency and the Job's plots, the following extraction reaction (1) is proposed;

$$
G a^{3+}+H_{4} L \Leftrightarrow G a \cdot H L+3 H^{+} \quad: K_{\mathrm{ex}}
$$

where $\mathrm{H}_{4} \mathrm{~L}$ represents the calix[4]arene derivative. From the fact that both extractants exhibit similar extraction ability differences from that expected based on the $\mathrm{p} K_{\mathrm{a}}$ values, the chelation together with phenoxy oxygen atoms and carboxylic acids of ${ }^{\mathrm{t} O c t}[2] \mathrm{Ac}-{ }^{3} \mathrm{Ben}$, which reduced the extraction ability was suggested as described above. For confirmation, the next experiment was carried out. 

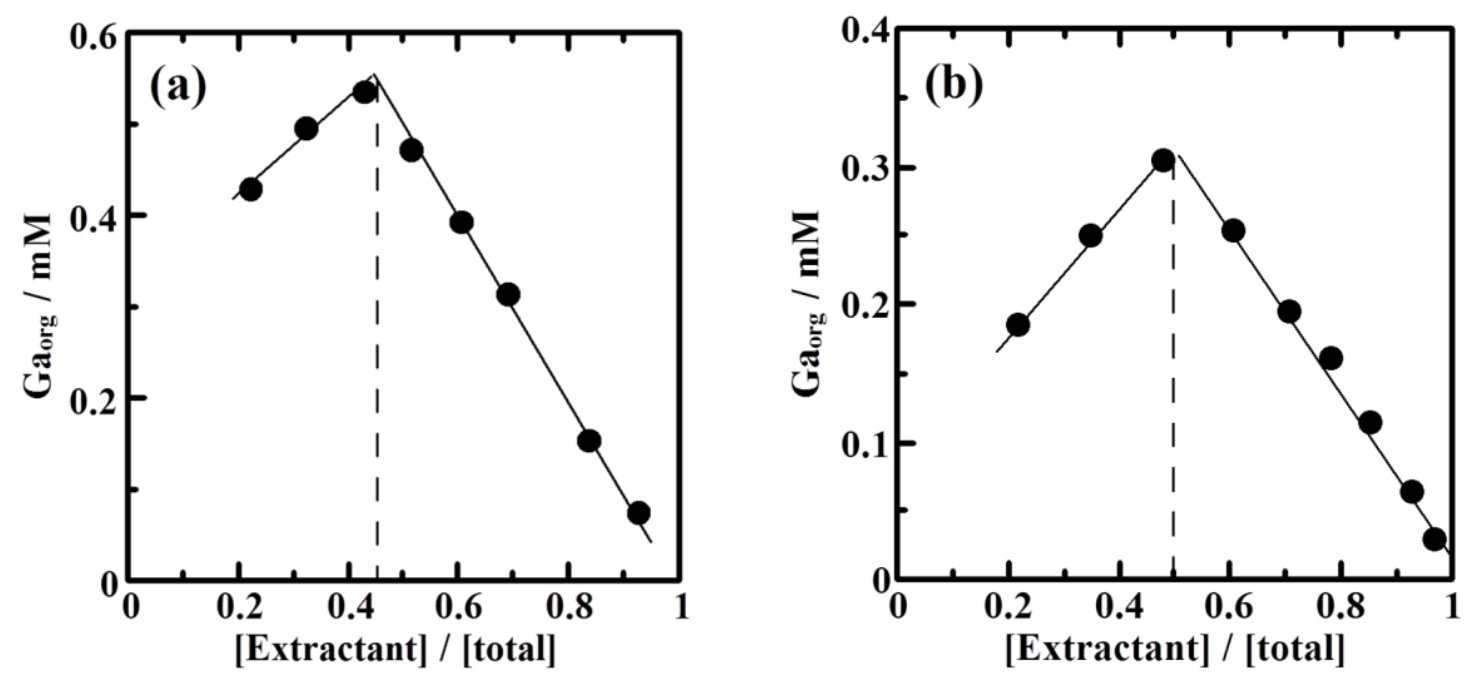

Figure 6. Job's plots for gallium with (a) ${ }^{\text {t} O c t[4] A c, ~(b) ~}{ }^{\text {t } O c t[2] A c-}{ }^{3} \mathrm{Ben}$ in chloride media. $\left[\mathrm{Ga}^{3+}\right]+[$ Extractant $]=1 \mathrm{mM}$, initial $\mathrm{pH}=4.15(0.1 \mathrm{M} \mathrm{HCl}-0.1 \mathrm{M} \mathrm{HEPES})$.

\subsection{Proton nuclear magnetic resonance study of the main complexes}

A proton nuclear magnetic resonance study was carried out to determine the coordination site for gallium with ${ }^{\mathrm{t} O c t}[2] \mathrm{Ac}-{ }^{3} \mathrm{Ben}$. The ${ }^{1} \mathrm{H}-\mathrm{NMR}$ spectra of ${ }^{\mathrm{t}} \mathrm{Oct}[2] \mathrm{Ac}-{ }^{3} \mathrm{Ben}$ before and after complexation with gallium are shown in Figure7. Since two peaks at 6.62 and 7.04 ppm derived from aryl protons of the calixarene framework were hardly shifted after complexation with gallium, the phenoxy oxygen atoms barely contribute to complexation contrary to our expectation. On the other hand, methylene protons derived from acetic acid (4.63 ppm) and aryl protons between the carboxylic acid and the methylene group in benzoic acid (8.35 ppm) both shifted to a higher magnetic field at 4.57 and $8.26 \mathrm{ppm}$, respectively. The shifts are apparently caused by complexation. Thus, the different extraction ability between the two extractants is mainly attributed to less complementarity and the structural rigidity of ${ }^{t} \mathrm{Oct}[2] \mathrm{Ac}-{ }^{3} \mathrm{Ben}$ compared with ${ }^{\mathrm{t} O c t}[4] \mathrm{Ac}$. The proposed complex structure of ${ }^{t} \mathrm{Oct}[2] \mathrm{Ac}^{3} \mathrm{~B}$ Ben with gallium is shown in Figure 8. The coordination number of gallium in the present work may be 4 .

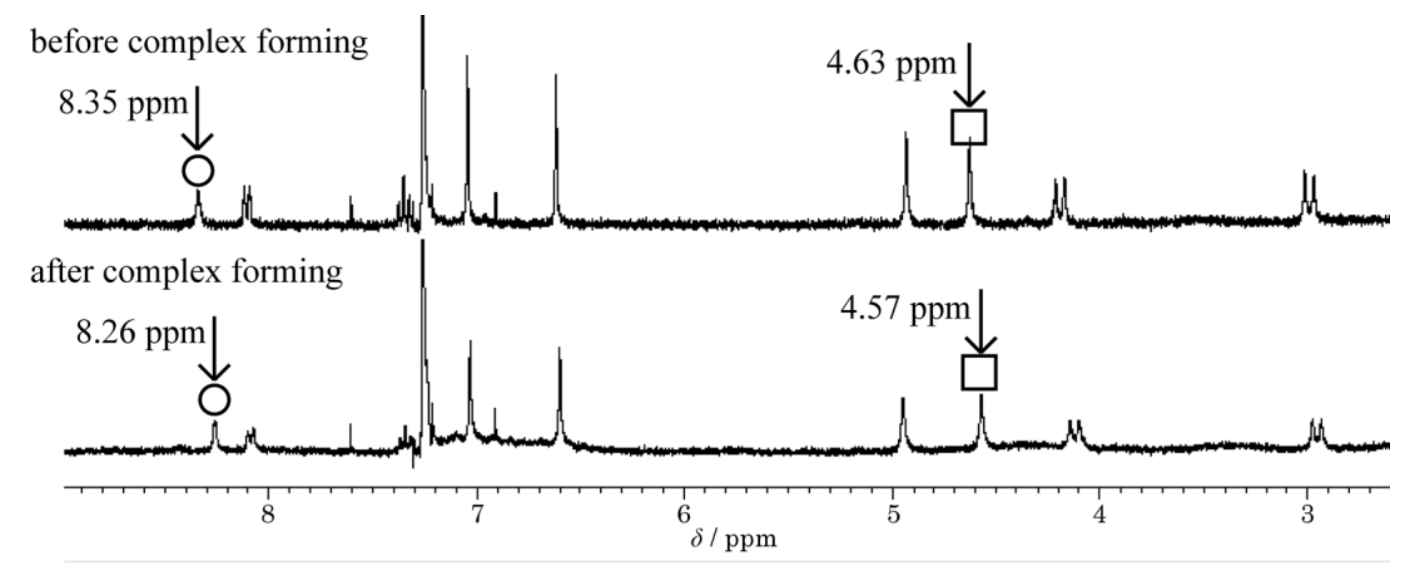

Figure 7. ${ }^{1} \mathrm{H}-\mathrm{NMR}$ spectra of ${ }^{\mathrm{t}} \mathrm{Oct}[2] \mathrm{Ac}-{ }^{3} \mathrm{Ben}$ before and after the complexation with gallium. 


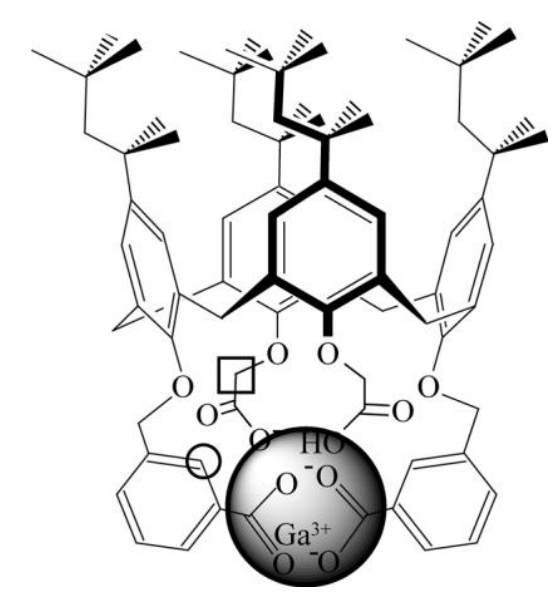

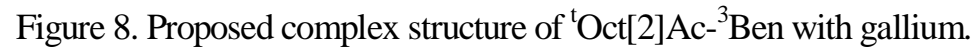

\subsection{Stripping of the loaded metal ions}

From an industrial point of view, stripping of the loaded metal ions is also important. The effect of hydrochloric acid concentration on percentage stripping of the metal ions loaded on ${ }^{\mathrm{t} O c t}[2] \mathrm{Ac}^{3}{ }^{3} \mathrm{Ben}$ is shown in Figure 9. The result suggests that complete stripping is achieved by hydrochloric acid at a concentration greater than $0.01 \mathrm{M}$ for the loaded indium and aluminum ions, and $0.1 \mathrm{M}$ for the loaded gallium ion.

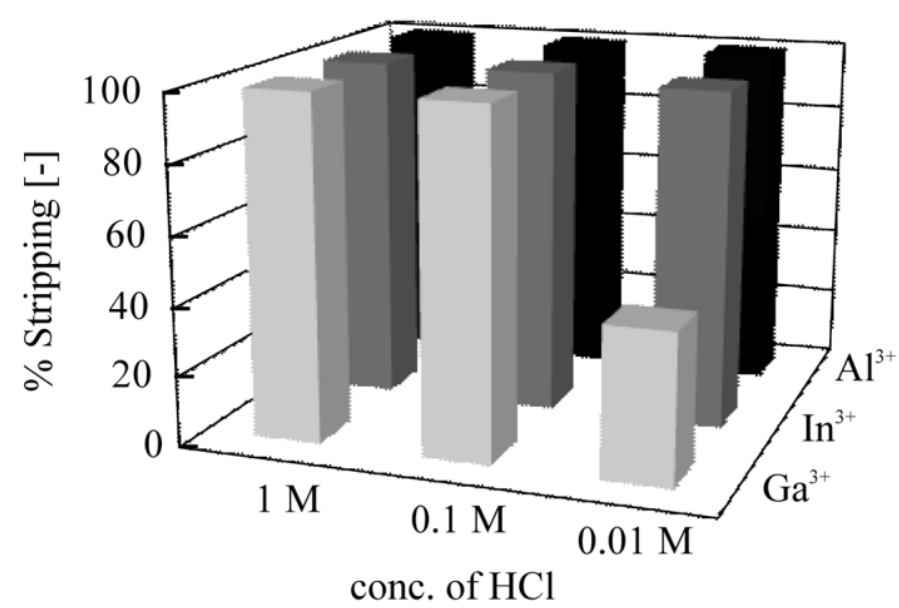

Figure 9. Effect of hydrochloric acid concentration on

percentage stripping of metal ions loaded on ${ }^{t} \mathrm{Oct}[2] \mathrm{Ac}-{ }^{3} \mathrm{Ben}$.

\section{Conclusion}

A benzoic acid - acetic acid crossed type of calix[4]arene derivative has been prepared to investigate extraction behavior for three aluminum group metal ions from nitrate and chloride media and to compare with the tetraacetic acid derivative. The present extractant exhibits a simple ion-exchange mechanism for all metal ions examined. Both extractants show selectivity to be $\mathrm{In}>\mathrm{Ga} \gg>\mathrm{Al}$ in nitrate media compared with $\mathrm{Ga}>\mathrm{In}>\mathrm{Al}$ in chloride media due to the strong complexation of indium with chloride ion. The stoichiometry of gallium with 
both extractants by the continuous variation method was determined to be $1: 1$. The complexation site of the present extractant with gallium was also determined by using ${ }^{1} \mathrm{H}-\mathrm{NMR}$ spectroscopy. The extraction ability and separation efficiency of both extractants for the three metal ions were estimated by using their half $\mathrm{pH}$ values. The difference in the extraction ability between the two extractants is mainly attributed to less complementarity and the structural rigidity of the present crossed type extractant. Stripping of the metal ions loaded on the present extractant with hydrochloric acid was also investigated. Complete stripping is achieved by hydrochloric acid at a concentration greater than $0.01 \mathrm{M}$ for the loaded indium and aluminum ions, and $0.1 \mathrm{M}$ for the loaded gallium ions.

\section{References}

1) K. Uezu, Q. T. H. Le, S. Umetani, P. Comba, Solv. Extr. Res. Dev., Jpn., 13, 161-173 (2006).

2) K. Kurahashi, S. Umetani, and Y. Sohrin, Solv. Extr. Res. Dev., Jpn., 15, 37-44 (2008).

3) K. Ohto, Y. Fujimoto, H. Furugou, H. Kawakita, H. Harada, K.Inoue, Solvent Extraction:Fundamentals to Industrial Applications, Proc.ISEC 2008, Int. Solv. Extr. Conf., Vol.2, 1481-1486 (2008).

4) S. Kanemaru, T. Oshima, Y. Baba, Solv. Extr. Res. Dev., Jpn., 16, $57-67$ (2009).

5) T. Kai, T. Oshima, Y. Baba, Solv. Extr. Res. Dev., Jpn., 17, 175-186 (2010).

6) C. D. Gutsche (ed.), Calixarenes Revisited. Royal Society of Chemistry, Cambridge (1998).

7) Z. Asfari, V. Boehmer, J. M. Harrowfield, J. Vicens (ed.),, Calixarenes 2001, Kluwer Academic Publishers, Netherlands (2001).

8) Y. K. Agrawal, S. Kunji, S. K. Menon, Rev. Anal. Chem., 17(2), 69-139 (1998).

9) R. Ludwig, J. Fresen. Anal. Chem., 367(2), 103-128 (2000).

10) K. Ohto, Solv. Extr. Res. Dev., Jpn., 17, 1-18 (2010).

11) T. Yoneyama, K. Ohto, H. Harada, H. Kawakita, Solv. Extr. Res. Dev., Jpn., 17, 187-194 (2010).

12) B. B. Adhikari, M. Gurung, H. Kawakita, K. Ohto, Analyst, 136, 4570-4579 (2011).

13) K.Ohto, T.Matsufuji, T.Yoneyama, M.Tanaka, H.Kawakita, T.Oshima, J. Incl. Phenom. Macrocycl. Chem., 71(3,4), 489-497 (2011).

14) T.Yoneyama, H.Sadamatsu, S.Kuwata, H. Kawakita, K. Ohto, Talanta, 88, 121-128 (2012).

15) K. Ohto, M. Yano, K. Inoue, T. Yamato, M. Goto, F. Nakashio, S. Shinkai, T.Nagasaki, Anal. Sci., 11(6), 893-902 (1995).

16) K. Ohto, Y. Fujimoto, K. Inoue, Anal. Chim. Acta., 387(1), 61-69 (1999).

17) M.Eigen, Pure Appl. Chem., 6, 97-115 (1963).

18) C. H. Wu, React. Kinet. Catal. Lett., 90(2), 301-308 (2007). 